\title{
Likes para a ciência: divulgação científica e consumo de notícias na página I Fucking Love Science no Facebook
}

\author{
Talyta Singer \\ Universidade Federal da Bahia \\ E-mail: ytasinger@gmail.com
}

\begin{abstract}
Resumo
Este trabalho pretende analisar a distribuição de conteúdo científico em sites de rede social usando como estudo de caso a página I Fucking Love Science no Facebook. Criada em 2012, a página conta com 20 milhões de likes, superando

com vantagem outras publicações mais tradicionais. Os resultados apontam que mesmo que seja feito uso de humor e expressões pouco convencionais, a cobertura não se distingue de mídias mais tradicionais.
\end{abstract}

Palavras-chave: divulgação científica; Facebook; I Fucking Love Science.

\section{Resumo}

This work aims to analyze the distri- more traditional publications. The results bution of scientific content on social show that even if it is made use of hunetworking sites using as a case study the mor and unconventional expressions, copage I Fucking Love Science on Face- verage does not differ from the one on book. Founded in 2012, the page has 20 more traditional media.

million likes, surpassing advantageously

Palavras-chave: science communication; Facebook; I Fucking Love Science.

\section{A estudante que amava ciência}

$\mathrm{E}$

LISE Andrew, uma estudante de biologia britânica, então com 23 anos, criou a página I Fucking Love Science em março de 2012. Lá ela colocou todo o conteúdo sobre ciência que costumava publicar em seu perfil pessoal e no dia seguinte já acumulava mais de 1000 seguidores (Wills, 2013). 
Atualmente, a página conta com 20 milhões de fãs, superando com bastante vantagem outras instituições mais tradicionais como Discovery News $(5,5 \mathrm{mi}$ lhões), Scientific American (2,1 milhões) e mesmo o The New York Times (9,3 milhões).

O conteúdo das publicações compreende divulgação de resultado de pesquisas, fotos curiosas, quadrinhos e memes de conteúdo científico. A abordagem, mesmo nas publicações mais sérias, é divertida. Na definição de uma das responsáveis pela página, enquanto o noticiário de ciência se dedica a cobrir o que é importante ou digno de nota, o IFLS tenta descobrir o que as informações tem de "cool"(Fitts, 2014).

Além do Facebook, IFLS tem perfil no Twitter, ativo desde setembro de 2012, o tem pouco mais de 150 mil seguidores. O canal do YouTube tem 230 mil inscritos. O primeiro vídeo foi publicado em agosto de 2013 e na época circularam notícias de que poderia ser produzidos programas para televisão, para o Science Channel (Lewis, 2014). O canal não publica novos vídeos há onze meses, o que parece indicar que o projeto foi cancelado. A expansão do conteúdo em outras redes também foi uma tentativa de gerar receita, conforme indica Andrew em entrevista dada em 2013:

YouTube has a revenue share option, Facebook doesn't. The only way to make money is to sell merchandise. We sell T-shirts. I donate a lot of the money to charity, the rest is reinvested or used for expenses. I could be making a lot of money; sites offer to pay me to link to them exclusively, but I like our independence and don't want to lose our readers' trust. I have a full-time job in Toronto, handling the social media content of LabX [a media group]. I like the stability of a regular pay cheque. If I were a starving student, I might have said yes to some offers, but I can afford to pick and choose. (Teeman, online, 2013)

O site foi lançado entre setembro e outubro de 2012. Elise disse que o criou para publicar notícias com sua própria voz, ao invés de apenas compartilhar conteúdos criados por outras pessoas (Teeman, 2013). Muitas das publicações da página não compartilhadas diretamente do site, onde as notícias são assinadas por membros de uma equipe que a falta de um expediente não permite identificar com clareza. 
Likes para a ciência: divulgação científica e consumo de notícias na página I

Uma das motivações de Andrews para manter a página é o tipo de respostas positivas que recebe. Desde professores que aproveitam alguns dos conteúdos para levar humor a salas de aula (Stoianovici, 2013) a adultos que gostam de acompanhar o que acontece na ciência, até mesmo cientistas que se atualizam sobre outras áreas de conhecimento (Teeman, 2013).

\section{Visibilidade e críticas}

O rápido crescimento da página fez com que ela fosse notícia em diversas publicações, incluindo Guardian (Teeman, 2013), BBC (Stoianovici, 2013), Mashable (Wills, 2013) e o assunto de capa da Columbia Journalism Review em setembro de 2014. Essa atenção dada ela imprensa, algumas imprecisões em informações divulgadas e o retrato feito pela CJR foram motivo de críticas feitas por Nadia Drake no site da Knight Science Journalism (Drake, 2014). Entre as críticas, já foi dito que a abordagem da IFLS e de outros veículos de divulgação científica é pouco crítica, confunde natureza com ciência, além de usar técnicas de click-baiting, técnica usada para gerar tráfego em sites a partir de textos provocativos e manchetes publicas em sites de rede social. Falando ao News Statement sobre imprecisões nas informações, Andrew se defendeu das críticas:

I've never shown things that were inaccurate. Somebody tried to troll Reddit and faked a Neil Degrasse Tyson quote, and I shared it not realising it was a fake. With quotes it's much more difficult to track; it's something that happened to go online, and it's difficult to keep track of who said what and when. I'm using quotes less now. (Woolf, online, 2012)

O maior problema, porém, parecem ser a falta de crédito ou referências no conteúdo divulgado, principalmente imagens. Alex Wild, que escreve para o blog Conpound Eye da Scientific American apresentou o problema (Wild, 2013). Após ver uma de suas fotos ser utilizada pela página sem créditos, ele analisou 100 fotos publicadas pela página e descobriu que 59\% não tinham qualquer crédito ou indicação de fonte. 


\section{Divulgação científica e consumo de informação no Facebook}

O Facebook é o maior site de rede social (SRS) da atualidade com mais de 1,3 bilhão de perfis ativos. Além de manterem seus perfis, os usuários passam grandes períodos de tempo conectados na plataforma. Pesquisa da empresa de análise de dados Flurry estimou que o Facebook ocupa 17\% do tempo gasto em dispositivos móveis, conta 1,5\% do Twitter e 3\% de aplicativos de notícias em geral (Khalaf, 2014).

Grande parte do tempo gasto no Facebook, assim como em outros SRS, é usado para consumo de notícias. Em 2014, a Pew Research identificou metade dos usuários do Facebook e do Twitter usam redes sociais para encontrar notícias, assim como $62 \%$ dos usuários do Reddit. E para muitos destes usuários o ambiente é mais importante do que a fonte, uma vez que $78 \%$ das pessoas que consumem notícias no Facebook usam essa rede social por outros motivos, que não consumir notícias. Apenas 34\% segue páginas de organizações jornalísticas ou jornalistas, o que sugere que a maior parte do conteúdo vem de sua rede de amigos e dos conteúdos que estes amigos curtem e compartilham (Malsa \& Mitchell, 2014).

Apesar do Facebook já ter seu lugar em algumas áreas da pesquisa social como sociabilidade e publicidade online, as pesquisas de distribuição de notícias na plataforma ainda estão em estágio inicial (Caers et al, 2013). Muito em função da própria estrutura que não permite a recuperação fácil do conteúdo e uma vez que propõe um consumo do fluxo de informação pautada no ao vivo (Kaun \& Stiernstedt, 2014).

Deste modo, para compreender o resultados da pesquisa nos apoiaremos na longa tradição de pesquisas que acompanham como diferentes mídias tratam dos temas de ciência e tecnologia. É o caso dos trabalhos de Auberguini (2007) e Ricci (2010). Estudos mais recentes mostram as relações entre a divulgação científica e as novas mídias, em especial Liang et al. (2014) e Veltri (2013).

\section{Coleta de dados}

Inicialmente, a proposta consistia em analisar 30 dias de publicações feitas na páginas entre dezembro de 2014 e março de 2015 selecionadas através de um calendário aleatório. Para a coleta do dados foi usado o scraper de- 
Likes para a ciência: divulgação científica e consumo de notícias na página I

senvolvido por Norah Abokhodair, ferramenta que extrai informações de uma página web. Entretanto, a ferramenta apenas captura o texto publicado diretamente no Facebook. No caso do IFLS, a maior parte do conteúdo textual está na visualização dos links compartilhados do site, sendo os textos publicados diretamente no Facebook comentários mais vagos que não permitem identificar $\mathrm{o}$ assunto tratado.

Os textos foram então capturados diretamente da página, mas não foi possível resgatar completamente o conteúdo, o que fez com que a amostra fosse reduzida a um mês de publicação contínua entre 12 de fevereiro de 2015 e 12 de março de 2015, resultando em 204 itens. As informações catalogadas foram data da publicação, texto publicado diretamente no Facebook, título do link quando compartilhado de outro site, título da imagem, contagem de likes, comentários e compartilhamentos. A amostra final foi composta por 202 itens, uma vez que em duas publicações não foi possível registrar a contagem de likes, comentários e compartilhamentos em função de uma mudança no layout do Facebook. A coleta das publicações e a contagem das interações foram feitas no dia 29 de março de 2015.

A segunda etapa consistiu em classificar os posts a partir do seu conteúdo explícito. As categorias foram criadas a partir de nossas expectativas e adaptadas a partir dos conteúdos encontrados. A classificação final é:

1. Conteúdo: Notícia, Propaganda, Imagem e vídeo, Infografia, Humor, Citação ou Campanha.

2. Área científica: O conteúdo, informativo ou não, foi classificado de acordo com a área científica da qual ele fazia referência. Encontramos 16 áreas representadas, a saber: Agricultura, Arqueologia, Astronomia, Biologia, Engenharia/Tecnologia, Física, Geologia, História da Ciência, Letras/Linguística, Matemática, Medicina, Meio Ambiente, Método, Nutrição, Paleontologia e Química.

3. Pessoas citadas: Também foram identificadas as pessoas citadas nas publicações, cientistas ou não.

4. Análise da rede da página: Outra etapa da coleta foi a extração de dados através do Netvizz (Rieder, 2013). A rede da página compreende outras páginas curtidas pela IFLS e páginas que curtem a IFLS. O objetivo desta análise era observar o posicionamento da IFLS frente a outras páginas e observar como é o espaço que ela ocupa dentro desta rede. 


\section{Resultados}

Tipicamente, os conteúdos publicados pela página são link para o site IFLS ou imagens com algum comentário curto ou expressão de sentimento, de modo que o Facebook seja uma porta de entrada para o conteúdo do site. Os comentários que apresentam funcionam mais como legendas com informações adicionais, como nos exemplos abaixo:

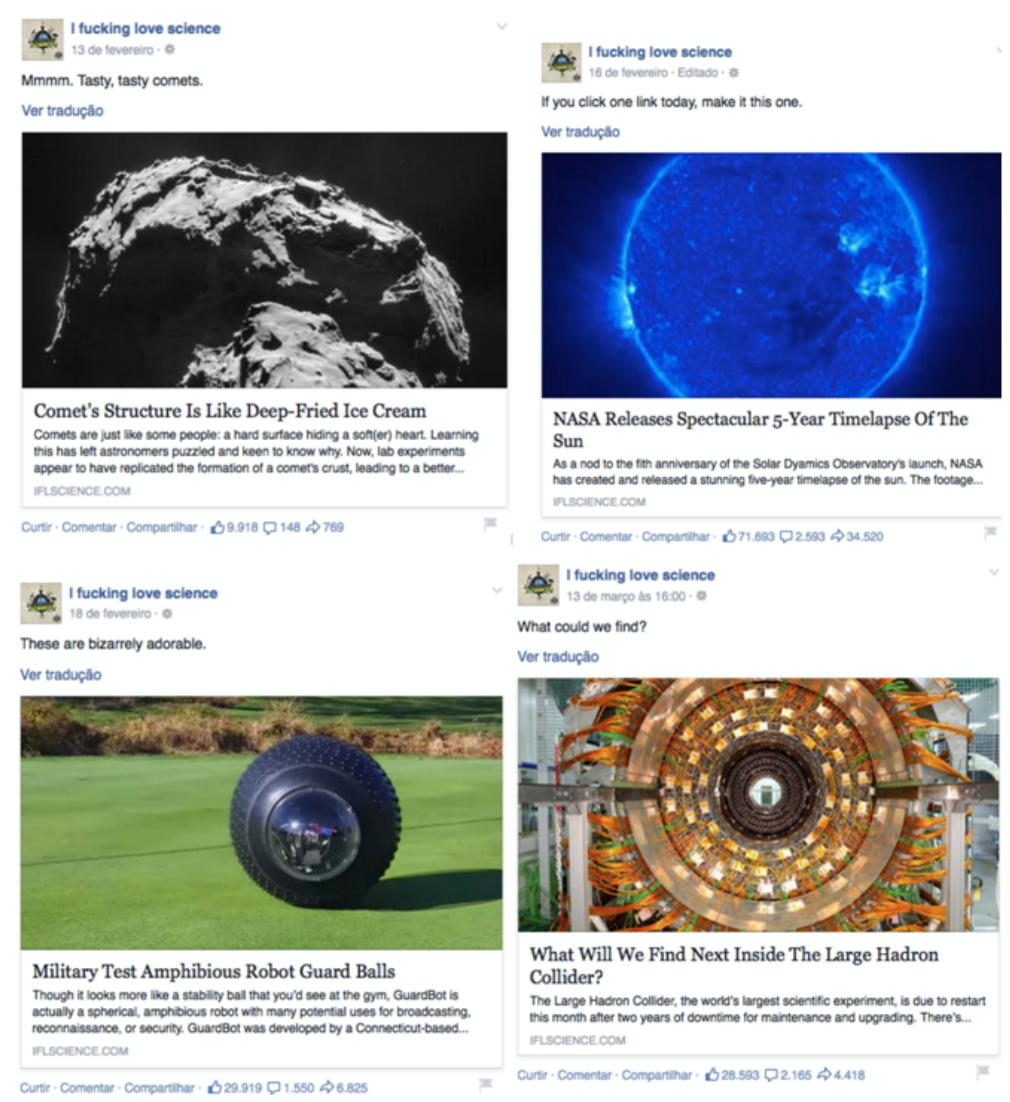

Figura 1 - Publicações da página I Fucking Love Science Fonte: Página I Fucking Love Science no Facebook 
Likes para a ciência: divulgação científica e consumo de notícias na página I Fucking Love Science no Facebook

A maior parte do conteúdo publicado pela página no período estudado é de notícias, que somam $64 \%$ das publicações. A divisão dos conteúdos por tipo de conteúdo é a seguinte:

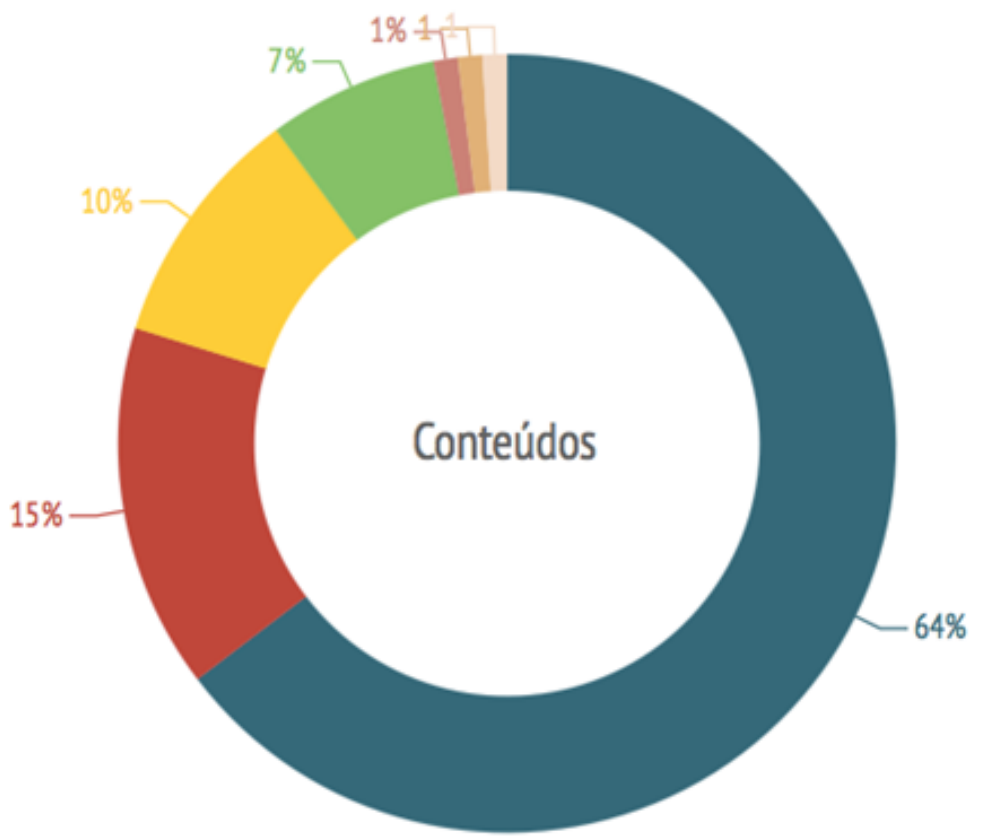

\section{Notícia Infografia Humor Imagem/Video Propaganda}

\section{Citação}

Figura 2 - Tipos de conteúdo

Elaboração própria

A incidência de notícias ou de publicações humorísticas varia de acordo com a área científica em destaque. Conteúdos ligados a Medicina e Astronomia eram mais frequentemente notícias, enquanto que conteúdos das áreas de Física, Matemática e Método científico tinham maior incidência de infogra- 
fias. Química é a área científica que mais vezes foi retratada em tom humorístico.

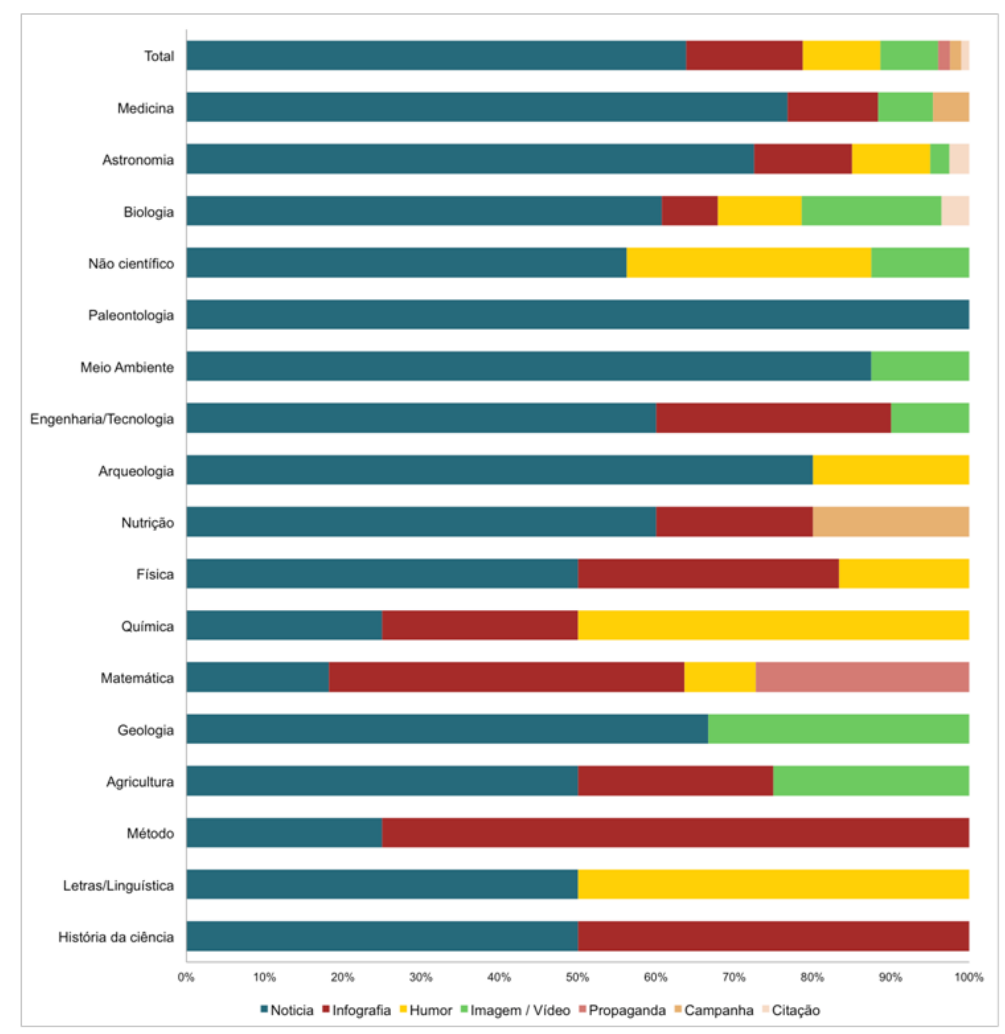

Figura 3 - Tipo de conteúdo por área científica Elaboração própria

Dentre 2020 publicações, 27 citam pessoas nominalmente. Ao todo são citados 37 cientistas, 2 cosmonautas, 2 comediantes, 1 pescador, Bill Nye, the Science Guy, Leonard Nimoy, o ator que interpretou Capitão Spock na série clássica de Star Trek, e o Capitão Kirk. Apenas 3 pessoas são citadas mais de duas vezes. $\mathrm{O}$ astrônomo Neil deGrasse Tyson, com quatro citações, lidera a lista. Ada Lovelace e Marie Curie são citadas três vezes. 
Likes para a ciência: divulgação científica e consumo de notícias na página I Fucking Love Science no Facebook

Analisamos ainda como as interações se distribuíam pela publicações e encontramos resultados interessantes. No primeiro gráfico comparamos a quantidade de posts por área científica em comparação com os índices de interação média que a categoria recebeu. Para calcular a interação média, somamos as contagens de likes, comentários e compartilhamentos e dividimos pela quantidade de publicações que cada uma das áreas científicas recebeu.

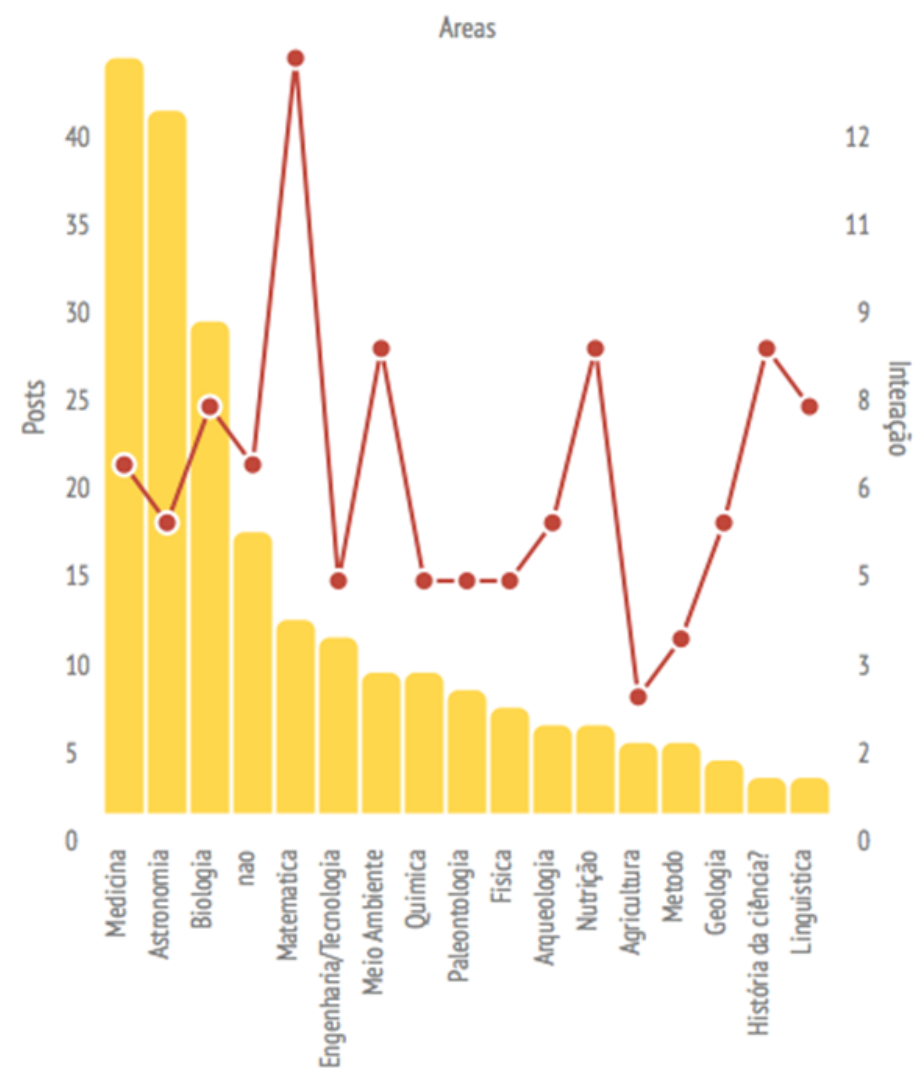

Posts

$$
\text { Interação }
$$

Figura 4 - Interação médias das publicações por área científica Elaboração própria 
Comparamos também a quantidade de posts por tipo de conteúdo e os índices de interação que cada um recebeu, como mostra a imagem abaixo:

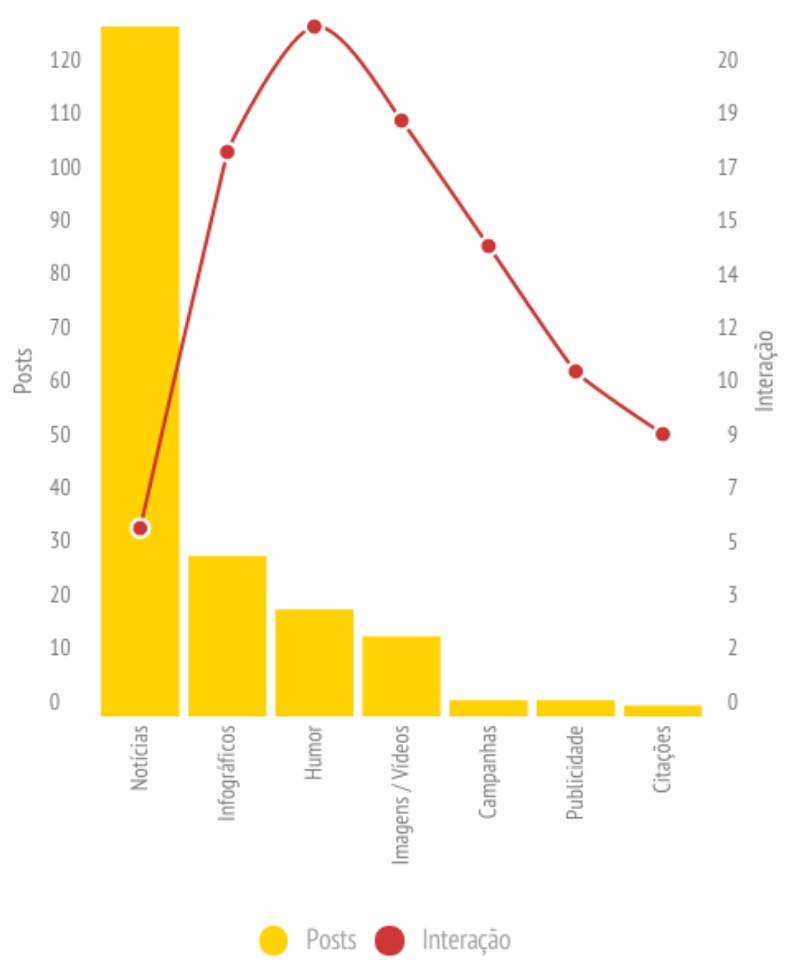

Figura 5 - Interação média dos posts por tipo de conteúdo

Por fim apresentamos um grafo que mostra a rede da página. Foi possível identificar sete diferentes tipos de páginas, representados pelas sete diferentes cores. A quantidade de likes que cada página recebeu define o seu tamanho na rede e suas relações com outras páginas definem sua posição. Como a rede foi gerada a partir da IFLS ela ocupa uma posição central, já que se relaciona com a maioria das páginas visualizadas e em maior tamanho por receber mais curtidas.

Analisando os grupos é possível perceber uma concentração de páginas de temática ambiental relacionadas com preservação marinha. No lado oposto da 
Likes para a ciência: divulgação científica e consumo de notícias na página I

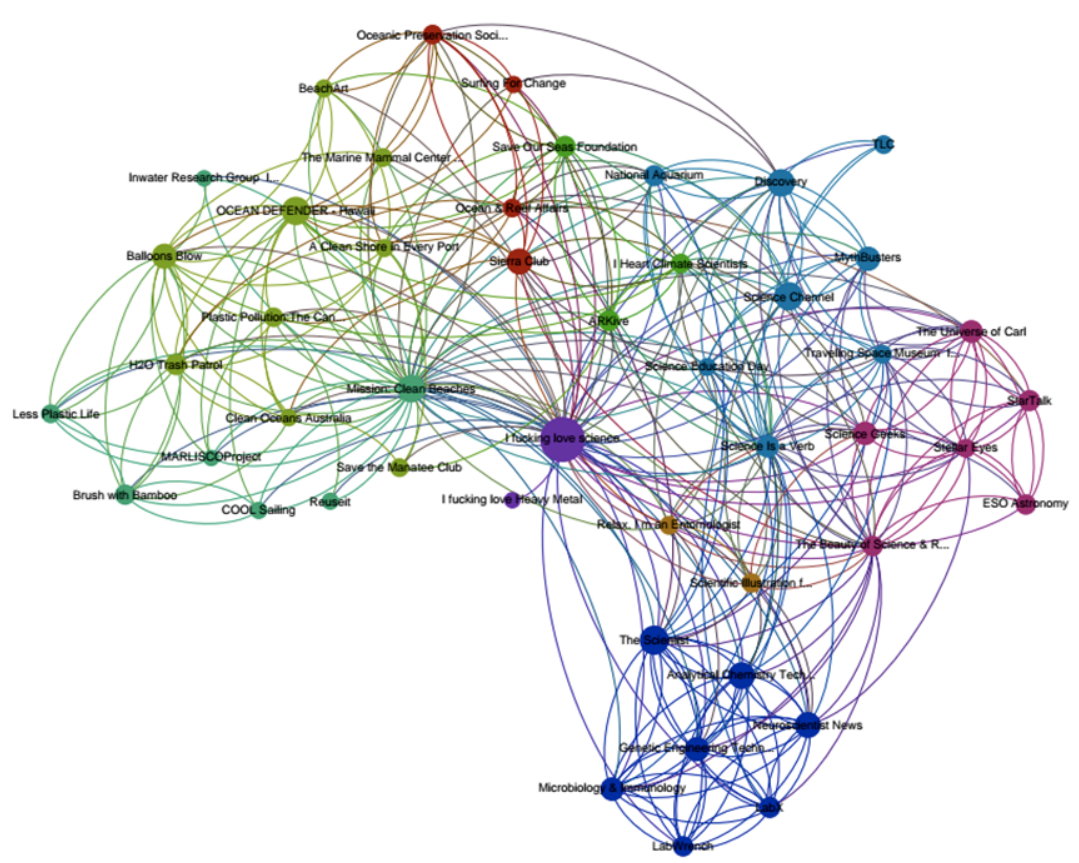

Figura 6 - Rede da página IFLS

imagem podemos ver as páginas de divulgação científica que formam três grupos. Concentradas na parte de baixo da imagem páginas ligadas a instituições mais tradicionais, algumas delas parte do Media X Lab empresa onde trabalha Elise Andrew. Do lado direito, na parte superior, em azul páginas de divulgação científica com perfil mais educativo como o Science Channel e Myth Busters. Science is a Verb é uma página que também parece funcionar como ponto de acesso e liga estes dois grupos. Finalmente, ocupando a parte direita dois grupos concentram páginas de divulgação científica mais divertidas. Em rosa um grupo de páginas ligadas à astronomia e em laranja páginas onde a maior parte dos conteúdos é de ilustrações. 


\section{Discussão}

A partir dos resultados encontrados podemos dizer que a página I Fucking Love Science se ocupa primariamente de noticiar, informar e compartilhar conteúdo humorístico relacionados às Ciências Exatas, Biológicas e da Saúde. Engenharias e Ciências Agrárias também são representadas, mas apenas quatro assuntos das área de Letras, Artes e Humanidadess foram registrados: Arqueologia, Método Científico e Letras/Linguística e História da Ciência, todos com pequeno número de conteúdos. É importante notar que registramos os conteúdos relacionados à método na área de humanas porque todos podem ser inscritos em áreas mais próximas a filosofia da ciência. Nominalmente, não é citado nenhum cientista destas áreas. A concentração na divulgação das ditas ciências duras já foi observada em outros trabalhos (Auberguini, 2007; Shaffer, 2010).

A concentração temática também pode ser observada nos cientistas mais citados. Neil DeGrasse Tyson, além de cientista, é uma figura midiática importante. Ele é o apresentador da reedição da série Cosmos e tem três milhões de seguidores no Twitter. A grande maioria dos cientistas citados nominalmente tem pesquisas de grande repercussão histórica como Marie Curie e Albert Einsten ou de grande visibilidade midiática como Jane Goodall e Stephen Hawking. O mesmo comportamento tem precedentes na literatura e é conhecido como "Saganization" effect (Liang et al, 2014), em referência a Carl Sagan, e acontece quando cientistas mais engajados midiaticamente acabam tendo mais impacto acadêmico do que seus colegas menos engajados.

O modo de narrar utilizado pela página e os formatos de conteúdo utilizados nos permitem dizer que se trata de uma página de jornalismo científico, ainda que ocorram publicações voltadas para o humor, principalmente se assumirmos o jornalismo científico em termos de uma atividade educativa e de popularização de conhecimento como faz José Marques de Melo (1982, p. 21):

E o que deve ser o jornalismo científico? Deve ser uma atividade principalmente educativa. [...] Deve promover a popularização do conhecimento que está sendo produzido nas nossas universidades e centros de pesquisa, de modo a contribuir para a superação dos muitos problemas que o povo enfrenta. Deve utilizar linguagem capaz de permitir o entendimento das informações pelo ci- 
Likes para a ciência: divulgação científica e consumo de notícias na página I

dadão comum. Deve gerar o desejo pelo conhecimento científico permanente, despertando interesse pelos processos científicos e não pelos fatos isolados e seus personagens.

A seleção de conteúdos da página parece atender a critérios de noticiabilidade variados, incluindo senso de oportunidade, timing, impacto, significado, pioneirismo, interesse humano, personagens célebres, proximidade, necessidades culturas e necessidade de conhecimento (Epstein, 2007).

As diferenças registradas entre a concentração de publicações e os maiores índice de interação podem funcionar como boas medidas para compreender que a página busca publicar conteúdo de qualidade ao invés de apenas alimentar seus seguidores com os tipos de conteúdos que geram mais interação. A maior parte das interações acontecem nos conteúdos humorísticas, mas não é este tipo de conteúdo que domina as publicações.

Vale destacar que isso não parece ser um impedimento ao modelo de negócios assumido pela página, uma vez que os conteúdos relacionados à Matemática geraram os maiores índices de interação, sendo que a maior parte deles fazia referencia ao Dia do Pi, celebrado em 14 de março, quando a data do calendário corresponde a primeira sequência de números da constante matemática $p i=3,1415$ e alguns deles direcionavam à loja IFLS que vendia camisetas comemorativas. Todas as propagandas registradas se referem à esta situação.

A página também não se furta de aderir a campanhas como é o caso das publicações contra o movimento anti-vacina e solicitando que a rede de fastfood Subway altere a receita de seus pães.

A grande visibilidade que os posts alcançam também merece nota. No período estudado a página acumulou 22 milhões de interações somando likes, comentários e compartilhamentos. O grande número de interações aponta que os conteúdos são recebidos também por pessoas que não seguem a página. O feed de notícias da plataforma personaliza o conteúdo exibido para cada usuário a partir de seu histórico de navegação e preferências. E do mesmo modo que nem todos os 20 milhões de fãs recebam todas as publicações, é possível dizer que sejam visualizadas por um número maior de pessoas graças ao volume de interações.

É necessário comentar o Facebook ao mesmo tempo em que concentra um grande número de pessoas dificulta o uso das informações para pesquisa. A falta de ferramentas que permitam extrair dados em maior profundidade e 
recuperar conteúdos passados é um empecilho para compreender como funcionam os mecanismos de interação ao longo do tempo. Conforme avança a importância da plataforma para distribuição de notícias será necessário desenvolver novas ferramentas.

Para finalizar, algumas limitações dos resultados da pesquisa devem ser mencionadas. A análise dá conta de um mês das publicações de uma página específica. Ainda que o número de publicações e de interações sejam altos, os resultados não podem ser generalizados para fora de seu contexto inicial. Para compreender melhor os mecanismos de divulgação científica usados pelo I Fucking Love Science seria ideal avaliar os textos completos publicados no site, que em função de espaço e foco, este artigo não avaliou. Além disso, não fizemos qualquer avaliação da recepção dos conteúdos que não fosse a contagem das interações. Em estudos posteriores pode ser interessante avaliar o que dizem os comentários e se a página interage diretamente com seus seguidores, promovendo o diálogo ou ampliando discussões.

\section{Referências bibliográficas}

Abokhodair, N. (s.d.). Facebook post browser. Disponível em: http://groupbrowser.azurewebsites.net.

American Press Institute (2015). How Millennials Get News: Inside the habits of America's first digital generation. Disponível em: www.americanpressinstitute.org.

Rieder, B. (2013). Studying Facebook via data extraction: the Netvizz application. WebSci '13 Proceedings of the 5th Annual ACM Web Science Conference: 346-355. New York: ACM.

Cacciatore, M.A.; Anderson, A.A.; Choi, D.H.; Brossard, D.; Scheufele, D.A.; Liang, X.; Ladwig, P.J.; Xenos, M. \& Dudo, A. (2012). Coverage of emerging technologies: A comparison between print and online media. New Media \& Society, 14(6): 1039-1059.

Caers, R. \& De Feyter, T. (2013). Facebook: A literature review. New Media \& Society, 15(6): 982-1002.

Drake, N. (2014, 04 de setembro). Guest Post: Elise Andrew, science popularizer with a spotty attribution record, gets a pass from CJR. Knight Science Journalism. Disponível em: https://ksj.mit.edu. 
Likes para a ciência: divulgação científica e consumo de notícias na página I

Epstein, I. (2007). Quando um fato se transforma em notícia no jornalismo e na ciência. Comunicação e Sociedade, 28(27): 159-179.

Fitts, A. (2014, setembro). Do you know Elise Andrew?. Columbia Journalism Review. Disponível em: www.cjr.org.

Khalaf, S. (2014, 01 de abril). Apps Solidify Leadership Six Years into the Mobile Revolution. Flurry. Disponível em: www.flurry.com.

Lewis, T. (2014, 10 de março). Craig Ferguson to Produce New Series 'I Fing Love Science'. Scientific American. Disponível em: www.scientificamerican.com.

Liang, X.; Su, L.Y.; Yeo, K.S.; Scheufele, D.A.; Brossard, D.; Xenos, M.; Nealey, P. \& Corley, E. (2014). Building Buzz: (Scientists) Communicating Science in New Media Environments. Journalism \& Mass Communication Quarterly, 91(4): 772-791.

Marques de melo, J. (1982). Impasses do jornalismo científico: notas para o debate. Comunicação e Sociedade, IV(7): 19-24. São Paulo.

Matsa, K.E. \& Mitchell, A. (2014, 26 de março). 8 Key Takeaways about Social Media and News. Pew Journalism. Disponível em: www.journalism.org.

Ricci, O. (2010) Technology for everyone: representations of technology in popular Italian scientific magazines. Public Understanding of Science, 19(5): 578-589.

Schäfer, M.S. (2010) Taking stock: A meta-analysis of studies on the media's coverage of science. Public Understanding of Science, 21(6): 650-663.

Stoianovici, A. (2013, 25 de janeiro). Mad about science. Interview with Elise Andrew, creator of I Fucking Love Science. BBC Science World. Disponível em: www.scienceworld.ro.

Teeman, T. (2014, 13 de outubro). Why millions love Elise Andrew's science page. The Guardian. Disponível em: www.theguardian.com.

Veltri, G.A. (2012). Microblogging and nanotweets: Nanotechnology on Twitter. Public Understanding of Science, 22 (7), 832-849, 2012.

Wild, A. (2013, 23 de abril). Facebook's "I F*cking Love Science" does not f*cking love artists. Scientific American. Disponível em: http://blogs.scientificamerican.com. 
Wills, A. (2013, 11 de setembro). Why Everyone F*cking Loves Science and Elise Andrew. Mashable. Disponível em http://mashable.com.

Woolf, N. (2012, 12 de dezembro). Nick Elise Andrew: "There is a lot of pseudo-science and nonsense out there on the internet". News Statement. Disponível em: www.newstatesman.com. 